\title{
A Construção de Protocolos Para Atenção Básica na Defesa do Direito à Saúde
}

\author{
Leandro Farias Rodrigues ${ }^{1}$, Marcos Aurélio Matos Lemões ${ }^{2}$, \\ Liamara Denise Ubessi ${ }^{3}$, Celmira Lange ${ }^{4}$, Daniele Luersen ${ }^{5}$
}

\begin{abstract}
RESUMO
Objetivo: Discutir a construção de protocolos para Atenção Básica na defesa do direito à saúde. Método: Estudo qualitativo, descritivo, tipo relato de experiência com observação participante em oficinas realizadas pelo Departamento de Atenção Básica do Ministério da Saúde. Resultados: problematização do uso de protocolos no Sistema Único de Saúde (SUS), função, conteúdos, métodos de construção e temas prioritários sob a perspectiva da clínica ampliada, apoio matricial e educação permanente em saúde. Destacados como tecnologia de cuidado podendo contribuir para a sustentação de práticas na Atenção Básica salvaguardado o risco de seu engessamento, reorganização do processo de trabalho, fomento ao trabalho em equipe, à produção de saúde sob o prisma da integralidade e contribuição na garantia da exequibilidade do direito à saúde. Considerações finais: A potência dos protocolos no fortalecimento da Atenção Básica e garantia do direito à saúde dependerá de como serão utilizados no cotidiano das práticas no SUS.
\end{abstract}

Palavras-chave: Protocolos. Atenção primária à saúde. Direito à saúde. Trabalho.

THE CONSTRUCTION OF BASIC ATTENTION PROTOCOLS FOR THE DEFENSE OF THE RIGHT TO HEALTH

ABSTRACT

Objective: To discuss the construction of Basic Attention protocols for the defense of the right to health. Method: This is a qualitative and descriptive study, a kind of experience report with participant observation in workshops carried out by the Department of Basic Attention of the Ministry of Health. Results: It was observed some questioning about the use of protocols in the Unified Health System (Brazilian SUS), their function, content, construction methods and priority issues from the perspective of extended clinic, matrix support and continuing education in health. Highlighted as a care technology that can contribute to sustaining practices in Primary Care, safeguarding the risk of making them inflexible, reorganizing the work process, fostering teamwork, health production under the prism of integrality and contributing to the guarantee of feasibility of the right to health. Final considerations: The power of the protocols in strengthening of Basic Care and guaranteeing the right to health will depend on how they will be used in the daily practices of SUS.

Keywords: Protocols. Primary health care. Right to health. Work.

Recebido em: 7/6/2017

Aceito em: $26 / 12 / 2018$

\footnotetext{
Enfermeiro. Especialização em Atenção Psicossocial no Âmbito do SUS pela Universidade Federal de Pelotas (UFPel, 2011-2012) e em Serviço no Departamento de Atenção Básica (DAB) no Ministério da Saúde (MS) (Universidade Federal do Rio Grande do Sul - UFRGS, 2013-2014). Referência descentralizada do Programa Mais Médicos no Rio Grande do Sul pelo Departamento de Planejamento e Regulação da Provisão de Profissionais de Saúde (Depreps) da Secretaria de Gestão do Trabalho e da Educação na Saúde (SEGTS) do Ministério da Saúde (MS). Mestrando do Programa de Pós-Graduação em Enfermagem - UFPel. leandrofeo@hotmail.com

Enfermeiro. Doutor em Ciências da Saúde pela Universidade Federal de Pelotas - UFPel. Pesquisador do Grupo de pesquisa Processo Saúde Doença vinculado à Universidade Federal do Rio Grande - Furg-RS. enf.lemoes@gmail.com

${ }^{3}$ Doutoranda no Programa de Pós-Graduação em Enfermagem - área de concentração Ciências: Práticas Sociais em Enfermagem e Saúde. Graduanda em Filosofia pela UFPel. Integra o grupo de pesquisa As Três Ecologias de Félix Guattari - Ecologia Ambiental, Social e Mental/Furg/UFPel. liaubessi@gmail.com

${ }^{4}$ Enfermeira. Docente do Programa de Pós-Graduação em Enfermagem - Universidade Federal de Pelotas. celmira_lange@terra.com.br

${ }_{5}^{5}$ Acadêmica de Enfermagem da Universidade Federal de Pelotas. Bolsista de Iniciação Científica Pibic UFPel. dani_luersen@hotmail.com
} 


\section{INTRODUÇÃO}

O presente trabalho versa sobre o processo de construção de protocolos, que foi difundido pelo Departamento de Atenção Básica (DAB) do Ministério da Saúde (MS) em 2013. Foi deflagrado a partir das discussões quanto à tramitação do Projeto de Lei no 268, de julho de 2002, no 7.703/06 na Câmara dos Deputados, que dispõe sobre o exercício da Medicina, conhecido como Lei do Ato Médico (BRASIL, 2002).

Este Projeto de Lei, caso aprovado na íntegra de seu conteúdo, tenderia a trazer consequências significativas para o que se ampliou e qualificou em termos de acesso e qualidade da atenção em saúde (ARAÚJO; ROCHA, 2007; SILVEIRA; SENA; OLIVEIRA, 2011), desde a criação do SUS, que traz no seu bojo o trabalho em equipe, inter e multidisciplinar (BRASIL, 2012). A interferência nas práticas das categorias profissionais, no processo de trabalho, reverberaria na garantia do direito à saúde para a população no território brasileiro.

Devido a esse risco iminente que se colocava, de retrocessos no SUS, Conselhos de Classe, associações nacionais de ensino, categorias profissionais e estudantis e outros atores sociais, se mobilizaram de modo a partilhar com a sociedade essa proposta e o posicionamento contrário a ela no teor empreendido. Com essa movimentação, conseguiu-se vetos à "Lei do Ato Médico", os quais foram sancionados pela presidente Dilma Rousseff, por meio da Lei no 12.842, de 10 de julho de 2013 (BRASL, 2013).

Isso posto, o poder Executivo deveria fundamentar os vetos e apresentar novas propostas para garantir a execução de algumas práticas das áreas profissionais não médicas. Por essa razão e como forma de assegurar as práticas de todas as áreas que operam na saúde, surgiu a necessidade de o Ministério da Saúde elaborar protocolos que estivessem voltados para a Atenção Básica.

Importa registrar que na ausência desses vetos, a realização de procedimentos invasivos, diagnósticos e qualquer prescrição terapêutica seria exclusiva à profissão médica, prejudicando um rol extenso de práticas, como procedimentos executados pelos profissionais em equipe, muitos dos quais já consagrados no SUS. Também tenderia a uma maior burocratização das rotinas, elevaria as situações de judicialização, devido à centralização da demanda em uma categoria, com comprometimento de recursos que já são escassos na área da saúde (VENTURA et al., 2010).

Desse modo, a perspectiva de construção de protocolos para Atenção Básica surge como forma de sustentar os vetos à Lei do Ato Médico, garantir as práticas já consolidadas no SUS, segurança no que se avançou no direito à saúde, proteger do dispêndio de recursos em situações de judicialização, entre outras.

Além disso, a depender do modo como forem utilizados, os protocolos podem apoiar o trabalho em saúde, permear as relações entre os sujeitos envolvidos no cuidado, que é atravessado por disputas de sentido e significados, devido à variabilidade de saberes de núcleo e concepções de modelo de saúde (CAMPOS, 2000). Com base no exposto, este estudo propõe-se a discutir a construção de protocolos para Atenção Básica a partir do registro de oficinas difundidas pelo Departamento de Atenção Básica (DAB) do Ministério da Saúde.

\section{MÉTODO}

Pesquisa de natureza qualitativa, descritiva, tipo relato de experiência. Desse modo, não houve apreciação do Comitê de Ética por constar neste estudo a percepção do autor principal sobre sua vivência nas oficinas. Conforme Minayo (2010), essa forma de pesquisa envolve além da subjetividade, as relações humanas e sociais, tanto dos indivíduos e grupos investigados como dos(as) pesquisadores(as). Também, de acordo com Godoy (2013), compreende dados descritivos sobre pessoas, lugares e processos interativos, no contato do pesquisador com a situação estudada.

Para este trabalho utilizou-se da observação participante. Esta perspectiva facilita verificar como as pessoas avaliam a experiência vivida, como definem um problema e quais opiniões, sentimentos e significados encontram-se associados a determinados fenômenos (LERVOLINO; PELICIONI, 2001).

Deste modo, este relato apresenta dois momentos da realização de oficinas pelo MS, ocorridas nos anos de 2013 e 2014, visando à construção dos protocolos para a Atenção Básica. É prática do DAB a produção destes materiais e outros, sejam técnicos, didáticos e/ou orientadores em parceria com atores(as) externos(as), considerados(as) expertises nos temas a que se dedicam.

Igualmente, importa registrar que somente o primeiro autor deste escrito participou dessas oficinas, durante a realização de atividades referentes ao curso de Especialização em Serviço de Saúde Coletiva e Educação na Saúde pela Universidade Federal do Rio Grande do Sul - UFRGS - ocorridas no Departamento de Atenção Básica no Ministério da Saúde, no período de janeiro de 2013 a dezembro de 2014. Os demais autores contribuíram na sistematização das informações, redação e discussão dessa experiência. 
A primeira oficina foi realizada no dia 12 de dezembro de 2013, e a seguinte, no ano subsequente, em 3 de fevereiro, no auditório do Hospital Sírio-Libanês, em São Paulo/SP. Participaram dessas oficinas profissionais das áreas de Fisioterapia, Psicologia, Enfermagem, Medicina e Fonoaudiologia de diversas instituições.

Os participantes vinculavam-se ao Núcleo de Apoio à Saúde da Família (Nasf) de São Paulo/SP, Hospital Israelita Albert Einstein/SP, I-EP/Hospital Sírio-Libanês, Secretarias Municipais de Saúde de Curitiba/ PR, Manaus/AM e de São Mateus/ES, Universidade Estadual de Londrina/PR e a Fundação Cochrane e três facilitadores(as) com formação em Medicina e Enfermagem do Instituto de Ensino e Pesquisa do Hospital Sírio-Libanês e do DAB/MS.

As discussões ocorridas nas oficinas foram registradas em diário de campo, considerado uma ferramenta que pode contribuir no trabalho de pesquisa, pois tende a articular teoria e prática e confrontar com o conhecimento produzido (SOARES et al., 2011). A partir disso, as narrativas desses momentos de trabalho foram sistematizadas como "Memória das Oficinas", seguidas de discussão, problematização e apontamentos finais.

\section{MEMÓRIA DAS OFICINAS}

\section{A Primeira Oficina}

Os trabalhos iniciaram-se com a contextualização de como surgiu a necessidade de elaboração de protocolos para a Atenção Básica, realizada por pessoas vinculadas ao DAB/MS. Foi explicitado que decorreu de discussões sobre a necessidade de justificação e sustentação dos vetos ao Projeto de Lei do Ato Médico, de ampliação do campo de atuação de outras áreas profissionais na Atenção Básica.

Nessa perspectiva, objetivou-se demarcar que os protocolos contribuam para a afirmação de modos de trabalho em equipe e em rede, para evitar que o Ato Médico ameace a integralidade em saúde e sustentar os avanços no SUS na garantia deste direito.

Desse modo, foram mapeadas as categorias profissionais que integram os Núcleos de Apoio à Atenção Básica (Nasf) no Brasil, via Cadastro Nacional de Estabelecimentos de Saúde. Predominaram neste profissionais de Psicologia, Nutrição, Fonoaudiologia e Fisioterapia, entre outras.

Apresentadas a contextualização da necessidade de elaboração dos protocolos e essas informações, os(as) participantes na oficina entraram em consenso sobre a sua função como tecnologias de gestão do cuidado que permitem que todos os profissionais possam exercer o atendimento nos serviços de saúde e tomem decisões clínicas baseadas em conhecimentos e fontes que resguardem juridicamente suas práticas.

Na sequência problematizou-se sobre a nomenclatura do material a ser produzido, se manteriam protocolo ou designariam como diretriz terapêutica ou linha-guia. Optou-se por "protocolo".

Também foi pontuado com ênfase que os protocolos fossem ao encontro das necessidades que apontam para as realidades do SUS, conforme as particularidades de cada experiência loco-regional, nos mais diversos cenários brasileiros, E que fornecessem diretrizes para os municípios, no intuito de conterem ações comuns e específicas de cada núcleo profissional

Após, os participantes reuniram-se em dois grupos, dos quais emergiram discussões sobre qual o conteúdo, formato, finalidades e efeitos esperados dos protocolos. Nessas discussões foi recomendado que os protocolos não devessem se pautar sumariamente em agravos, para não produzir o efeito de deslocar a atenção somente para as doenças, que deveriam dialogar com materiais já existentes e que levassem em conta as "melhores evidências disponíveis", que consistem em integrar a experiência clínica individual com os melhores achados de estudos clínicos (SACKETT et al., 2003).

Além disso, que facilitassem a abordagem a situações de saúde sob uma perspectiva inter e multiprofissional, de compreensão de cada ciclo e momento da vida. O foco privilegiado seria o fortalecimento do campo de atuação das equipes neste design inter e multiprofissional, na perspectiva da clínica ampliada, com práticas e procedimentos que impactassem positivamente nos indicadores de saúde e na qualidade de vida, em prol do exercício de uma boa atuação profissional. E finalmente, que os protocolos contribuíssem para o processo de reorganização do trabalho.

Ao término desta primeira oficina ficou acordado que os participantes seguiriam as discussões em fórum virtual, via plataforma on-line disponibilizada pelo I-EP do Hospital Sírio-Libanês.

\section{A Segunda Oficina}

Considerado o acumulado da primeira oficina e discussões on-line, os participantes dividiram-se em grupos por seus núcleos profissionais, ocasião em que debateram o escopo de conteúdo de suas respectivas categorias. Vale ressaltar que muitos participantes utilizaram documentos e protocolos municipais como 
norteadores de seus debates o que, em alguns momentos, interferiu nos diálogos e ideias em torno do conteúdo proposto.

Desse debate despontaram como foco comum das discussões a reiteração de que os protocolos propiciassem o trabalho interdisciplinar e amparassem situações de categorias profissionais que realizam intervenções individuais e de apoio matricial na Atenção Básica.

Por conta dos prazos e como boa parte dos grupos afirmou atuar em diversas condições por ciclos de vida, o assunto do primeiro protocolo, decidido por consenso, foi sobre "Pré-Natal e Puerpério", o qual, atualmente, já se encontra disponível no site do DAB/ Ministério da Saúde (BRASIL, 2016).

Por decisão do coletivo de trabalho os protocolos seriam divididos em ações comuns, de campo, que são aquelas que podem ser realizadas por todos os profissionais na condição abordada, e ações específicas, de núcleo, que versariam sobre as atividades realizadas por cada categoria profissional.

Diante do consenso dos participantes, pactuaram-se os compromissos de participação no fórum on-line quanto à produção escrita das minutas referentes aos conteúdos. Na sequência foram acordados outros cinco encontros como forma de garantir a elaboração dos demais Protocolos da Atenção Básica.

Além disso, nessa processualidade de construção dos protocolos, foram feitos apontamentos pelos grupos sobre o conceito de apoio matricial e compreensões sobre transdisciplinaridade, ambos entendidos como transversais e fundamentais a essa discussão.

No que se refere ao Apoio Matricial, surgiram comentários, como sendo uma retaguarda especializada, de "supervisão" in loco, ferramenta para o compartilhamento do cuidado e como promotor de reflexões e mudanças no cotidiano de trabalho.

Nesta mesma perspectiva ocorreu a discussão quanto ao temário da transdisciplinaridade. Embora todos os núcleos tivessem tematizado a questão da disciplinaridade, houve momentos de tensionamentos entre os participantes da oficina sobre a importância da transdisciplinaridade na elaboração dos protocolos. Alguns reconheciam sua importância, outros argumentavam que ela interfere na função dos profissionais na Atenção Básica, pois poderia haver extrapolação de práticas que são de competência exclusiva do núcleo de alguns profissionais na área da saúde.
O narrado aqui ocupou-se de sistematizar o registrado no diário de campo quanto à participação nas duas primeiras oficinas de elaboração dos protocolos. Essas narrativas demonstram o processo democrático de sua construção, a preocupação para que se cumprisse com a função de estratégia que contribuísse para a reorganização do processo de trabalho, como fortalecimento da Atenção Básica, defesa do SUS e principalmente garantia do direito à saúde.

\section{PROTOCOLOS COMO SUSTENTAÇÃO DE PRÁTICAS NA ATENÇÃO BÁSICA}

O processo de construção de protocolos atenderia à necessidade que se colocou ante o risco de desmonte do SUS caso fosse aprovada a Lei do Ato Médico. Também, como respaldo a um modelo de saúde que vem sendo instaurado no Brasil, com aposta na Atenção Básica (AB) como a ordenadora do cuidado, que tem produzido efeitos na vida dos usuários em todo o território brasileiro (SILVA et al., 2016; MEDRADO; CASANOVA; OLIVEIRA, 2015).

Essa aposta na $A B$ tem em seus pilares de atuação o processo de trabalho em equipes inter, multi e transdisciplinares. Além disso, conta com a instituição do apoio matricial na permanente produção de redes a fim de se caminhar no rumo da integralidade, superando a lógica biomédica ainda presente que fragmenta o cuidado (OLIVEIRA et al., 2016; MENDES et al., 2016).

Sob essa perspectiva, o trabalho em equipe, possibilita a visão da situação de saúde de diferentes perspectivas, pois tende a ampliar a clínica, a escapar dos redutos queixa - conduta. Propõe-se a construir possíveis soluções com a pessoa que demanda pelos serviços de forma compartilhadas (MOREIRA et al., 2016). O trabalho em equipe estaria ameaçado com a proposta da Lei do Ato Médico. Juntamente com isso, o direito à saúde, dado que possivelmente ampliaria a burocratização e judicialização nos serviços de saúde, pois esta, conduzida em um sistema neoliberal não responde às necessidades principalmente dos usuários em situações de maior vulnerabilidade no Brasil.

Nessa esteira, os protocolos podem ser um elemento fundamental neste processo de salvaguardar as práticas de saúde construídas sobre as perspectivas da integralidade, e que têm produzido efeitos tais como: diminuição da mortalidade infantil, aumento da expectativa de vida e a política de atenção à HIV, entre outros (CARETI et al., 2016; CAMARGOS; GONZAGA, 2015; SOUSA; PINTO JÚNIOR, 2016). Do mesmo modo, podem servir como aparato legal para as práti- 
cas de saúde e contribuir para barrar os processos de sucateamento e desmonte do SUS e de transformação da vida das pessoas em mercadoria.

Além disso, mesmo sob essa perspectiva de contribuir na garantia do direito à saúde como bem social, o processo de discussão e construção dos protocolos de forma democrática serviria como dispositivo de educação permanente para os profissionais de saúde sobre os nós críticos de fluxos nos serviços de saúde, processos de trabalho, comunicação e compartilhamento do cuidado com outros pontos da rede de atenção.

Neste trabalho, o processo de construção dos protocolos considerou que estes funcionassem como um aparato teórico e legal às práticas de saúde, no exercício inter-multidisciplinar, conforme cada situação, ao encontro das necessidades apontadas na realidade cotidiana do SUS. Essa sinalização vai ao encontro do que argumente Scherer et al. (2016), de que a ideia de construção de protocolos não pode ficar refém da prescrição de normas e tarefas, desconsiderando as potencialidades e as singularidades dos sujeitos e situações de saúde.

Esse alerta também é feito por Campos (2010), ao mencionar que os protocolos deveriam estar noutra lógica que não a da racionalidade gerencial, a qual com a definição de condutas interfere na expressão da experiência do trabalhador, tornando-o objeto executor do escrito pelos "entendidos no assunto", que geralmente estão distantes de onde se realiza o cuidado. Explica porque há tantas críticas aos protocolos. $O$ fato não é que sejam bons ou ruins, mas sim, ao modo como são usados e a que lógica responderiam. $\mathrm{Na}$ saúde a perspectiva gerencial é pouco eficaz, pois o "objeto" da atenção são as pessoas e não de números, burocracias, ainda que estas existam.

A Fiocruz tem destacado que o uso de protocolos pode contribuir para a reorganização dos serviços (FIOCRUZ, 2009), para a democratização da gestão e atenção, para que assim o cidadão participe da decisão sobre o cuidado que precisa. São caminhos para ampliar a resolubilidade da equipe e integralidade em saúde. Nesse sentido, os protocolos podem contribuir também na qualificação profissional, reorganização do trabalho e qualificação da atenção, dado que tendem a ser elaborados por consenso de grupo de especialistas (CUNHA, 2010). Os protocolos devem ser adequados a cada realidade sanitária, envolvendo de forma democrática a participação dos atores locais.

Nesta perspectiva, Barbosa et al. observam que a elaboração de protocolos clínicos pode contribuir para fortalecer a Atenção Básica como a ordenadora do cuidado na rede (2016). Um estudo apontou, contudo, que há também necessidade de capacitação dos profissionais, a qual está relacionada à falta de preparo e desenvolvimento da política de educação permanente no que se refere a conteúdos básicos e até aos protocolos com temas mais específicos (SANTOS et al., 2016).

A prevalência de utilização dos protocolos é maior entre enfermeiros comparados a outros profissionais da equipe de saúde (SILVEIRA et al., 2010). Estudo sobre o agir profissional de equipes de saúde apontou que profissionais da Medicina tendem a não se integrarem às equipes. As que não contam com este profissional e utilizam de protocolos foram as que obtiveram melhores resultados na avaliação do PMAQ (GOMES; TOASSI; WARMLING, 2016). Contribui para as reflexões referente às motivações da defesa da Lei do Ato Médico e ao mesmo tempo coloca em questão a "hierarquia" de saberes e poderes e a necessidade de um professional desta área nas equipes de $A B$.

$O$ uso de protocolo, no entanto, só faz sentido se usado envolvendo a equipe de forma multi e interdisciplinar e usuários, de forma dialógica, na busca de consensos, o que asseguraria a todos a condição de sujeitos, com autonomia, principalmente a quem demanda e se volta o cuidado (CAMPOS, 2010). O protocolo interessa, deste que seja singularizado, pois se trata de práticas de saúde e não de técnicas (CAMPOS, 2012). Da mesma forma, pode ser um dispositivo de enfrentamento de propostas que compreende a agenda neoliberal, como o foi o projeto de Ato Médico.

Os protocolos não podem ser idealizados na garantia do direito à saúde, na reorganização do processo de trabalho, na gestão compartilhada, ampliação da clínica, lateralização de saberes e poderes, no enfrentamento da lógica neoliberal, pois quem os produz, por mais que tenha acúmulos nas práticas de saúde não necessariamente vivencia o cotidiano do SUS na Atenção Básica.

Mesmo assim, contudo, podem os protocolos contribuir em todas essas perspectivas, na afirmação da Atenção Básica como a principal porta de entrada no Sistema Único de Saúde, evitar judicializações e retrocessos na produção e garantia do direito à saúde, a depender de como forem utilizados no cotidiano dos serviços.

\section{CONSIDERAÇÕES FINAIS}

Este trabalho contribuiu para refletir sobre os limites, potencialidades e temas emergentes no processo de construção de protocolos multiprofissionais 
voltados para a Atenção Básica, a partir da Lei do Ato Médico e da conjuntura política instaurada no país. A experiência de construção de protocolos traz ao debate o dilema de que os protocolos podem engessar as práticas, enquadrando o cuidado e as pessoas em formatos de atenção preestabelecidos, justamente o que se contesta na produção da saúde.

Os protocolos podem ser tomados como tecnologias de gestão do cuidado, para amparar o exercício profissional de trabalhadores que atuam na Atenção Básica e fortalecer as políticas desenvolvidas no SUS por fomento ao trabalho interdisciplinar e multiprofissional, mas o seu uso dependerá da vontade política de adesão e efetivação pelos gestores e trabalhadores locais, além da pactuação de fluxos a fim de reorganizar o processo de trabalho em rede na saúde.

Por fim, a potência dos protocolos de contribuir com o fortalecimento da Atenção Básica na garantia do direito à saúde, na contraposição ao desmonte do SUS pela lógica privatista neoliberal que vem se instaurando no Brasil, dependerá de como serão ou não utilizados no cotidiano das práticas.

\section{REFERÊNCIAS}

ARAUJO, M. B. S.; ROCHA, P. M. Trabalho em equipe: um desafio para a consolidação da estratégia de saúde da família. Ciência \& Saúde Coletiva, v. 12, n. 2, p. 455-464, 2007. Disponível em: http://dx.doi.org/10.1590/S141381232007000200022. Acesso em: 4 set. 2016.

BARBOSA, N. C. T. et al. A educação permanente em saúde: uma análise dos projetos de intervenção apresentados por gestores de saúde durante a participação de um curso a distância. SIED-EnPED - Simpósio Internacional de Educação a Distância e Encontro de Pesquisadores em Educação a Distância. São Carlos, SP, 2016.

BRASIL. Congresso Nacional. Projeto de lei n. 268 de julho de 2002, no 7.703/06 na Câmara dos Deputados sobre o exercício da medicina. 2002. Disponível em: http://www. camara.gov.br/proposicoesWeb/prop_mostrarintegra;jsessionid=4433A08C449174F70AA875EB01DEA321. proposicoesWeb2 ?codteor $=432204 \&$ filename $=P L+7703 / 2006$. Acesso em: 4 set. 2016.

BRASIL. Ministério da Saúde. Política Nacional de Atenção Básica. Brasília, DF: Ministério da Saúde. 2012. Disponível em: http://189.28.128.100/dab/docs/publicacoes/geral/ pnab.pdf. Acesso em: 10 ago. 2016.

BRASIL. Ministério da Saúde. Protocolos da Atenção Básica: saúde das mulheres. Instituto Sírio-Libanês de Ensino e Pesquisa. Brasília: Ministério da Saúde, 2016. Disponível em: http://189.28.128.100/dab/docs/portaldab/publicacoes/ protocolo_saude_mulher.pdf. Acesso em: 2 dez. 2016.
BRASIL. Presidência da República. Casa Civil. Lei n. 12.842, de 10 de julho de 2013. Mensagem de veto. Dispõe sobre o exercício da medicina. 2013. Disponível em: http:// www.planalto.gov.br/ccivil_03/_Ato2011-2014/2013/Lei/ L12842.htm. Acesso em: 18 set. 2016.

CAMARGOS, M. C. S.; GONZAGA, M. R. Viver mais e meIhor? Estimativas de expectativa de vida saudável para a população brasileira. Cad. Saúde Pública, p. 1.460-1.472, 2015.CAMPOS, G. W. S. Cogestão e neoartesanato: elementos conceituais para repensar o trabalho em saúde combinando responsabilidade e autonomia. Ciência \& Saúde Coletiva, 15(5), p. 2.337-2.344, 2010. Disponível em: http:// sites.multiweb.ufsm.br/residencia/images/Disciplinas/ CAMPOS-\%20Cogestoe\%20mudana.pdf. Acesso em: 20 out. 2016.

CAMPOS, G. W. S. Saúde pública e saúde coletiva: campo e núcleo de saberes e práticas. Ciênc. Saúde Coletiva, 5(2), p. 393-403, 2000. Disponível em: http://dx.doi.org/10.1590/ S1413-81232000000200002. Acesso em: 18 set. 2016.

CAMPOS, G. W. S. Apoio matricial e práticas ampliadas e compartilhadas em redes de atenção. Psicologia em Revista, 18(1), p. 148-68, 2012. Disponível em: http://periodicos.pucminas.br/index.php/psicologiaemrevista/article/ view/3851/4155. Acesso em: 20 out. 2016.

CARETI, C. M. et al. Ações em saúde na atenção básica para redução da mortalidade infantil. Northeast Network Nursing Journal, v. 17, n. 1, 2016.CUNHA, G. T. A construção da clínica ampliada na atenção básica. 3. ed. São Paulo: Hucitec, 2010.

FIOCRUZ. Fundação Oswaldo Cruz. Dicionário da Educação Profissional em Saúde. Integralidade como princípio do direito à saúde. Escola Politécnica de Saúde Joaquim Venâncio. 2009. Disponível em: http://www.epsjv.fiocruz.br/ dicionario/verbetes/intsau.html. Acesso em: 20 out. 2016.

GODOY, A. S. Fundamentos da pesquisa qualitativa. In: TAKAHASHI, A. R. W. (org.). Pesquisa qualitativa em administração: fundamentos, métodos e uso no Brasil. São Paulo: Atlas, 2013. p. 35-50.

GOMES, J. C.; TOASSI, R. F. C.; WARMLING, C. M. O agir profissional de equipes de saúde e a atenção a gestantes no Sistema Único de Saúde. Saberes Plurais: Educação na Saúde, v. 1, n. 1, 2016.

LERVOLINO, S. A.; PELICIONI, M. C. F. A utilização do grupo focal como metodologia qualitativa na promoção da saúde. Rev. Esc. Enf. USP, 35(2), p. 115-121, 2001. Disponível em: http://dx.doi.org/10.1590/S0080-62342001000200004. Acesso em: 20 set. 2016.

MEDRADO, J. R. S.; CASANOVA, A. O.; OLIVEIRA, C. C. M. Estudo avaliativo do processo de trabalho das Equipes de Atenção Básica a partir do PMAQ-AB. Saúde em Debate, 39(107), p. 1.033-1.043, 2015. Disponível em: http://www.scielo.br/pdf/sdeb/v39n107/0103-1104-sdeb-39-107-01033.pdf. Acesso em: 10 dez. 2016. 
MENDES, F. R. P. et al. Representações sociais dos estudantes de enfermagem sobre assistência hospitalar e atenção primária. Rev. Bras. Enferm., 69(2), p. 343350, 2016. Disponível em: http://dx.doi.org/10.1590/ 0034-7167.2016690218i. Acesso em: 10 dez. 2016.

MINAYO, M. C. S. O desafio do conhecimento: pesquisa qualitativa em saúde. 10. ed. São Paulo: Hucitec, 2010.

MOREIRA, D. A. et al. Estratégias de organização e fortalecimento do trabalho na equipe de saúde da família. Revista de Enfermagem do Centro-Oeste Mineiro, v. 6, n. 1, jan./abr. 2016.

OLIVEIRA, L. A. et al. Processos microrregulatórios em uma Unidade Básica de Saúde e a produção do cuidado. Saúde em Debate, 40(109), p. 8-21, 2016. Disponível em: http:// dx.doi.org/10.1590/0103-1104201610901. Acesso em: 10 dez. 2016.

SACKETT, D. L. et al. Medicina baseada em evidências: prática e ensino. 2. ed. Porto Alegre: Artmed, 2003.

SANTOS, A. D. et al. Potencialidades e dificuldades nas práticas de acolhimento na rede de atenção básica conforme a Política Nacional de Humanização. Sau. \& Transf. Soc., Florianópolis, v. 6, n. 2, p. 54-69, 2016.

SCHERER, Magda Duarte dos Anjos et al. Cursos de especialização em Saúde da Família: o que muda no trabalho com a formação? Interface-Comunicação, Saúde, Educação, v. 20, n. 58, p. 691-702, 2016.

SILVA, S. S. et al. Uso de serviços de saúde por diabéticos cobertos por plano privado em comparação aos usuários do Sistema Único de Saúde no Município de Belo Horizonte, Minas Gerais, Brasil. Cad. Saúde Pública, 32(10). Disponível em: http://dx.doi.org/10.1590/0102-311X00014615. Acesso em: 20 out. 2016.
SILVEIRA, D. S. et al. Gestão do trabalho, da educação, da informação e comunicação na atenção básica à saúde de municípios das regiões Sul e Nordeste do Brasil. Cad. Saúde Pública, Rio de Janeiro, 26(9), p. 1.714-1.726, set. 2010.

SILVEIRA, M. R.; SENA, R. R.; OLIVEIRA, S. R. O processo de trabalho das equipes de saúde da família: implicações para a promoção da saúde. Rev. Min. Enferm., 15(2), p. 196-201, 2011. Disponível em: http://www.reme.org.br/artigo/detaIhes/25. Acesso em: 20 set. 2016.

SOARES, N. A. et al. O diário de campo utilizado como estratégia de ensino e instrumento de análise do trabalho da enfermagem. Rev. Eletr. Enf., 13(4), p. 665-670, 2011. Disponível em: https://www.fen.ufg.br/revista/v13/n4/pdf/ v13n4a10.pdf. Acesso em: 12 out. 2016.

SOUSA, A. I. A. de; PINTO JÚNIOR, V. L. Carga viral comunitária do HIV no Brasil, 2007-2011: potencial impacto da terapia antirretroviral (HAART) na redução de novas infecções. Revista Brasileira de Epidemiologia, v. 19, n. 3, p. 582593, 2016.

VENTURA, M. et al. Judicialização da saúde, acesso à justiça e a efetividade do direito à saúde. Physis, 20(1), p. 77-100, 2010. Disponível em: http://dx.doi.org/10.1590/S010373312010000100006. Acesso em: 1ㅇs. 2016. 